\title{
Influência da embalagem na intenção de compra do consumidor de suco de laranja industrializado
}

\author{
Influence of the package on consumer purchase intent of \\ processed orange juice
}

Leticia da Silva Freitas', Bárbara Pereira da Silva', Ceres Mattos Della Lucia’

' Universidade Federal de Viçosa, Departamento de Nutrição e Saúde, Viçosa-MG, Brasil

Contato: Bárbara Pereira da Silva - barbarapereira2805@gmail.com

\begin{abstract}
Resumo
Objetivo: avaliar a influência da embalagem na aceitação de suco de laranja industrializado pelo consumidor. Método: Foram estudadas cinco marcas de suco ( $A, B, C, D$ e E), as quais foram avaliadas em três etapas de testes: teste cego, teste com embalagem e teste com informação. Os testes foram aplicados em 51 julgadores, utilizando escala hedônica de 9 pontos. Os resultados foram analisados por meio de estatística descritiva e pelo teste de Tukey $(\alpha=0,05)$. Resultados: No teste cego, a marca E obteve melhor aceitação, diferindo das marcas A e B. No teste de embalagem, as marcas A, D e E não diferiram entre si, sendo a marca $C$ a de pior aceitação. Já no teste com informação, as marcas A, C, D e E não diferiram entre si. Conclusão: Os resultados indicam que a embalagem pode influenciar positiva ou negativamente a avaliação do consumidor sobre o produto.

Neste estudo, a informação sobre a marca exerceu influência positiva para as marcas A, B e C. Já para as marcas D e E, a informação sobre o produto diminuiu a porcentagem de consumidores que gostaram do produto, indicando que estes sucos podem ser preferidos quando as intervenções da marca são eliminadas.
\end{abstract}

Palavras-chave: Marca. Análise sensorial. Consumidor.

\begin{abstract}
Objective: To evaluate the influence of the package on the acceptance of processed orange juice. Methods: Five juice brands were studied (A, B, C, D and E), which were evaluated in three steps: blind test, packaging test and test with information. The tests were applied in 51 judges, using 9 points hedonic scale. The results were analyzed by descriptive statistic and by Tukey's test ( $\alpha=0.05$ ). Results: In the blind test, the brand E showed the best acceptance, differing of brands $A$ and B. In packaging test, brands A, D and E did not differ, and the brand C showed the worst acceptance. In the test with information, the brands A, C, D and E did not differ. Conclusion: The results indicate that the package can positively or negatively influence the consumer's assessment of the product. In this study, information on the brand had a positive influence on brands $A, B$ and $C$. For brands $D$ and $E$, product information decreased the percentage of consumers who liked the product, indicating that these juices may be preferred when the brand interventions are eliminated.
\end{abstract}

Keywords: Brand. Sensory analysis. Consumer. 


\section{INTRODUÇÃO}

Devido ao ritmo de vida acelerado da sociedade, o preparo de sucos de frutas naturais tornou-se uma dificuldade, o que contribuiu para o crescente interesse por parte do consumidor brasileiro em consumir produtos "prontos para consumo" ${ }^{\text {. Essa }}$ mudança impulsionou, a partir da década de 90, o surgimento de diversas marcas comerciais de sucos de frutas industrializados no mercado nacional ${ }^{2}$.

O Decreto $n^{0} 2.314$ do MAPA, de 1997, estabelece os Padrões de Identidade e Qualidade de bebidas, os registros, a classificação, a padronização e a rotulagem, bem como as formas de controle das matérias-primas, das bebidas e dos estabelecimentos. Neste Decreto encontra-se a definição de bebida, como sendo "todo produto industrializado, destinado à ingestão humana, em estado líquido, sem finalidade medicamentosa ou terapêutica". As bebidas são classificadas como bebidas não-alcoólicas ou alcoólicas. Os tipos e as definições das bebidas nãoalcoólicas são contempladas nos artigos 40 a 60 da Seção I, incluindo suco ou sumo (Art. 40), Polpa de fruta (Art. 41) e Néctar (Art. 43). Suco ou sumo é definido como: "a bebida não fermentada, não concentrada e não diluída, destinada ao consumo, obtida da fruta sã e madura, ou parte do vegetal de origem, por processo tecnológico adequado, submetida a tratamento que assegure a sua apresentação e conservação até o consumo". Na mesma Seção I também estão incluídas as definições de suco desidratado, suco misto, suco reconstituído, a designação do termo integral e a denominação concentrado para o suco parcialmente desidratado. O Decreto $n^{0} 3.510$, de 2000, acrescenta ao Art. 40 a definição de suco tropical ${ }^{3,4}$.

O Brasil é um dos maiores produtores de laranjas do mundo, respondendo por $60 \%$ da produção mundial, sendo o suco de laranja um dos seus principais produtos de exportação. $\mathrm{O}$ pais é ainda considerado o maior exportador de suco de laranja do mundo, sendo os principais importadores desse suco os Estados Unidos, União Europeia, Japão e China 5 . O estado de São Paulo é o maior produtor de suco de laranja. A área dedicada ao plantio da fruta nesse estado representa, em média, 62\% da área total de produção de laranjas no Brasil ${ }^{6}$.

Com o crescimento das empresas produtoras de suco de frutas, surgiram várias marcas no mercado, colocando estas empresas em grande concorrência entre si, ainda mais por ser um segmento novo e com potencial de expansão, o que acabou atraindo também a presença de empresas menores e regionais. Devido à saturação do mercado com produtos e marcas diferentes, o consumidor é abordado com, em 
média, 5 mil mensagens de marcas diariamente, o que dificulta cada vez mais a evidência de uma marca no mercado. Desta forma, uma marca tem que se diferenciar das outras para conquistar a confiança do consumidor7.

Para os consumidores, marcas vão além de apenas um símbolo ou logotipo, elas representam algo idealizado e desejado. A marca é definida pela American Marketing Association (AMA) como "um nome, termo, sinal, símbolo ou design, ou uma combinação de tudo isso, destinado a identificar os produtos ou serviços de um fornecedor ou um grupo de fornecedores para diferenciá-los dos de outros concorrentes". Portanto uma marca é um produto ou serviço que agrega dimensões que a diferenciam de outros produtos e serviços e é desenvolvida para satisfazer necessidades de consumidores. Essas diferenças que uma marca espera ter de outra estão relacionadas ao desempenho do produto ${ }^{8}$.

É nesse contexto que surge o valor de marca, que vai além dos valores da empresa. É por meio do valor de marca que o consumidor cria vínculos com o produto ou serviço que lhe ofereça os atributos desejados e idealizados por ele. Esse produto ideal e de desejo criado pelo consumidor nada mais é que a extensão da marca, onde o consumidor associa a marca à qualidade do produto, ao status oferecido por determinada marca, à influência de grupos sociais, à satisfação do uso, e à relação custo-benefício. Todos esses fatores interferem diretamente no processo de decisão de compra?.

Esse cenário ilustra a importância de se pesquisar esse mercado que a cada dia se expande, o que justifica o estudo das características não sensoriais que influenciam a compra de sucos industrializados, forma como o consumidor se comporta e o quanto a embalagem pode influenciar tanto positiva quanto negativamente a intenção de compra desse consumidor. Assim, o objetivo deste trabalho foi avaliar a influência da embalagem sobre a intenção de compra do consumidor de suco de laranja industrializado do município de Viçosa - MG.

\section{MÉTODO}

\section{Marcas de sucos de laranja amostradas}

Foram utilizados sucos de laranja industrializados nacionais, em embalagens Tetra Pak de 1 litro de cinco marcas diferentes. As marcas de sucos foram codificadas pelas letras de A a E e escolhidas de acordo com a disponibilidade das marcas no mercado 
de Viçosa, MG, uma vez que o experimento foi realizado com consumidores residentes nessa cidade.

\section{Testes de aceitação}

Foram recrutados 51 voluntários para compor a equipe sensorial dos testes de aceitação, entre estudantes e funcionários da Universidade Federal de Viçosa (UFV) e residentes da cidade de Viçosa (MG). O pré-requisito para o voluntário participar da pesquisa envolveu o hábito de consumir suco industrializado e a disposição para participar de todas as sessões de testes. A amostra selecionada não representa a população de consumidores de sucos industrializados brasileiros, mas serve como exemplo no estudo da influência de fatores ou características não sensoriais na aceitação do consumidor, além de permitir a demonstração de técnicas que podem ser utilizadas nesses tipos de trabalho.

Aos voluntários foi solicitado o preenchimento do questionário relativo aos seus dados demográficos e à frequência de consumo de suco industrializado. Os testes de aceitação foram conduzidos no Laboratório de Análise Sensorial do Departamento de Nutrição e Saúde, da UFV, em três sessões, com intervalos de, ao menos, oito horas entre as sessões, a fim de evitar a fadiga sensorial dos julgadores.

Na primeira sessão (sessão 1 ou teste-cego), os consumidores degustaram as amostras servidas em copos de plástico (capacidade $40 \mathrm{~mL}$ ) sem obter qualquer informação prévia sobre a marca do suco em avaliação. Nesta sessão, cada uma das cinco amostras foi codificada com número de três dígitos. Na segunda sessão (sessão 2 ou teste da embalagem) foi avaliada a aceitação das embalagens das amostras servidas na sessão anterior. Esse procedimento permitiu que o consumidor avaliasse, entre outros atributos da embalagem, a marca dos sucos em estudo.

A aceitação das amostras de sucos servidas juntamente com a respectiva embalagem foi realizada na terceira sessão (sessão 3 ou teste com informação). Foi solicitado ao consumidor que julgasse a bebida, atentando para o fato de que essa era proveniente do produto contido naquela embalagem.

As avaliações em cada sessão foram realizadas em cabines individuais, sob luz branca, sendo as amostras servidas de forma aleatória e monádica, sob temperatura de refrigeração $\left(6^{\circ} \mathrm{C} \text { a } 8^{\circ} \mathrm{C}\right)^{9}$. Em todas as sessões, o julgador recebeu uma ficha para cada amostra em que lhe foi solicitado que indicasse na escala hedônica de 9 pontos a sua aceitação em relação ao produto, atribuindo notas que variavam entre "gostei 
extremamente" (correspondente à nota 9) e "desgostei extremamente" (correspondente à nota 1$)^{9}$.

Os dados levantados a partir do questionário sobre características demográficas foram analisados em termos de distribuição de frequências das respostas obtidas.

A análise de frequência das notas hedônicas foi realizada na primeira etapa para cada marca e para cada sessão, conforme as seguintes faixas de aceitação: 1) notas hedônicas variando entre 1 e 5 (categorias situadas entre "desgostei extremamente" e "indiferente"), indicando que os consumidores desgostaram da amostra, e 2) notas hedônicas variando de 6 a 9 (categorias situadas entre "gostei ligeiramente" e "gostei extremamente"), mostrando que os consumidores gostaram da amostra. A categoria "indiferente" da escala hedônica foi considerada como resposta ruim, uma vez que consumidores indiferentes ao produto geralmente não são propensos a consumi-lo.

A análise de variância (ANOVA) foi realizada em cada sessão de aceitação das marcas de sucos. O teste de comparação de médias de Tukey, ao nível de $5 \%$ de probabilidade, foi utilizado para verificar se havia diferença em termos de aceitação entre as marcas utilizadas, em cada teste. As análises estatísticas foram feitas utilizando-se o programa Statistical Package for the Social Sciences (SPSS), versão 20.0. O presente trabalho foi aprovado pelo Comitê de Ética da Universidade Federal de Viçosa sob o número 118265/2015.

\section{RESULTADOS}

\section{Características demográficas dos consumidores}

Dos 51 participantes desde estudo, $78 \%$ eram do sexo feminino, e a faixa etária predominante $(58,8 \%)$ foi de 18 a 25 anos de idade. Ainda, $54 \%$ dos participantes possuíam curso superior incompleto e 34\% cursavam pós-graduação. Quanto à renda familiar mensal, 62,5\% dos participantes afirmaram ter renda entre um a cinco salários mínimos e apenas 2,1\% afirmaram receber acima de 20 salários mínimos (Figura 1).

Quanto ao perfil comportamental dos participantes (Figura 2), 23,5\% afirmaram consumir suco industrializado pelo menos 2 vezes por semana. Referente ao hábito de ler os rótulos dos produtos que consomem, 88,2\% relataram ter esse hábito, seguidos de 39,2\% que afirmaram ler frequentemente. As características citadas como as mais observadas nas embalagens foram: prazo de validade $(88,2 \%)$, 
informações nutricionais $(72,5 \%)$, informações sobre os ingredientes e preço $(64,7 \%)$, e a marca $(47,0 \%)$.

Figura 1 - Perfil demográfico dos consumidores participantes do estudo.

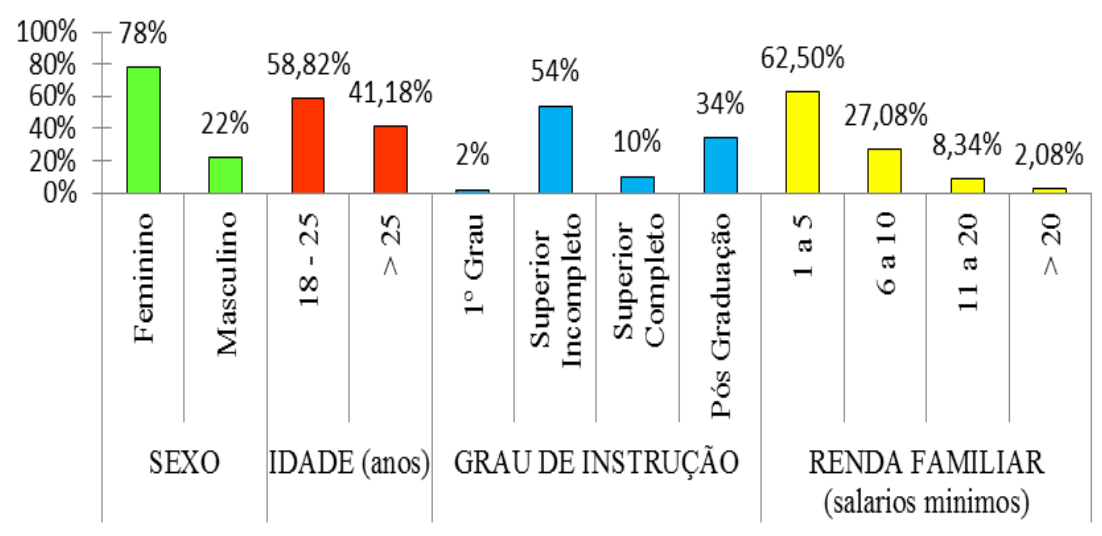

Figura 2 - Perfil de comportamento dos consumidores participantes do estudo.

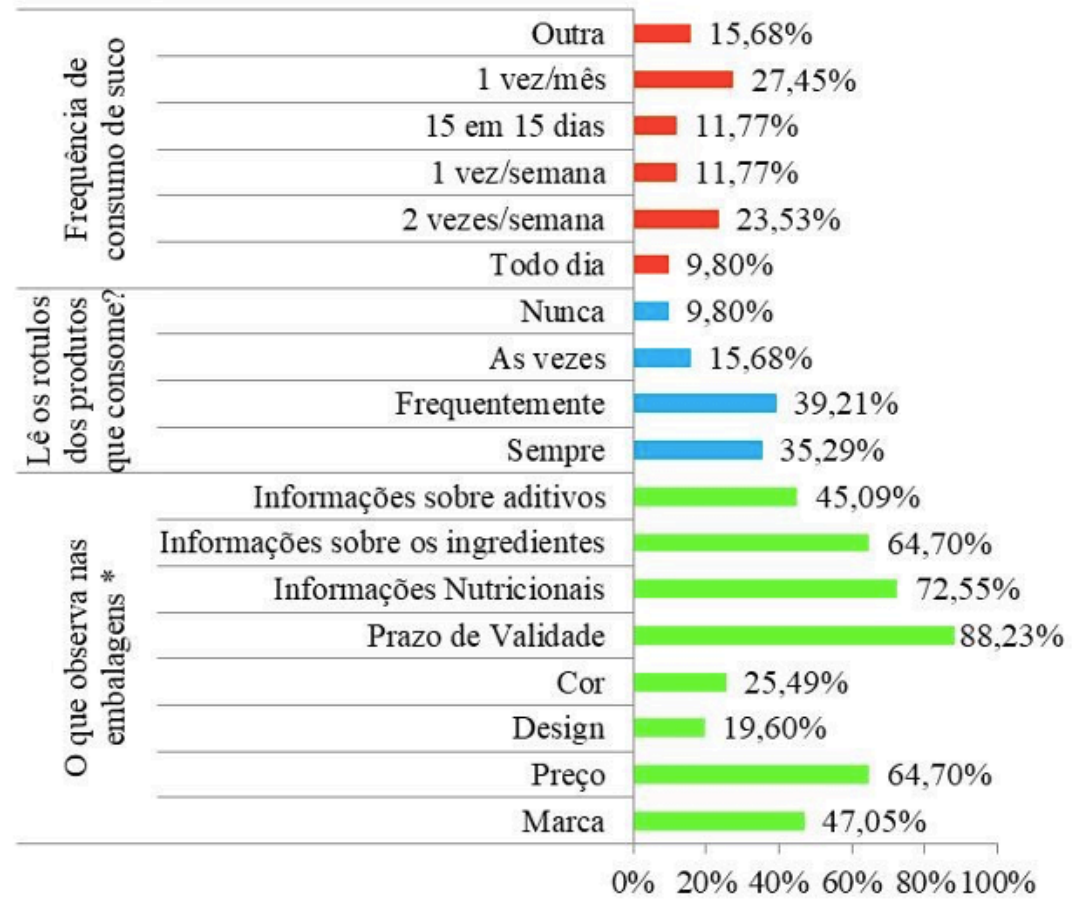

*Características com mais de uma descrição por consumidor, portanto são observadas somas de frequências maiores do que $100 \%$.

Em relação à existência de alguma marca de suco consumida com maior frequência pelos participantes da pesquisa, 93\% afirmaram consumir a marca A frequentemente (Figura 3). Dentre as marcas utilizadas neste estudo, somente a marca C não foi citada como sendo frequentemente consumida pelos participantes. 
Figura 3 - Frequência com que a marca foi mencionada pelos participantes como a mais consumida.

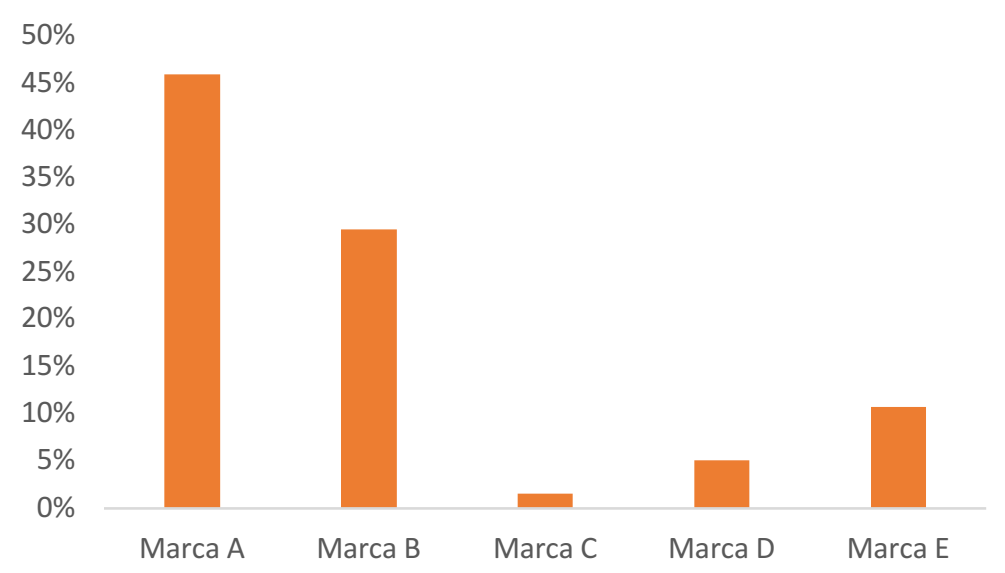

\section{Teste de aceitação}

Na Figura 4 está ilustrada a frequência das duas faixas de notas hedônicas (Faixa Amarela - Notas de 6 a 9, Faixa Vermelha - Notas de 1 a 5) para as marcas de suco de laranja industrializado, considerando as três sessões de aceitação sensorial.

Figura 4 - Frequência com que a marca foi mencionada pelos participantes como a mais consumida.

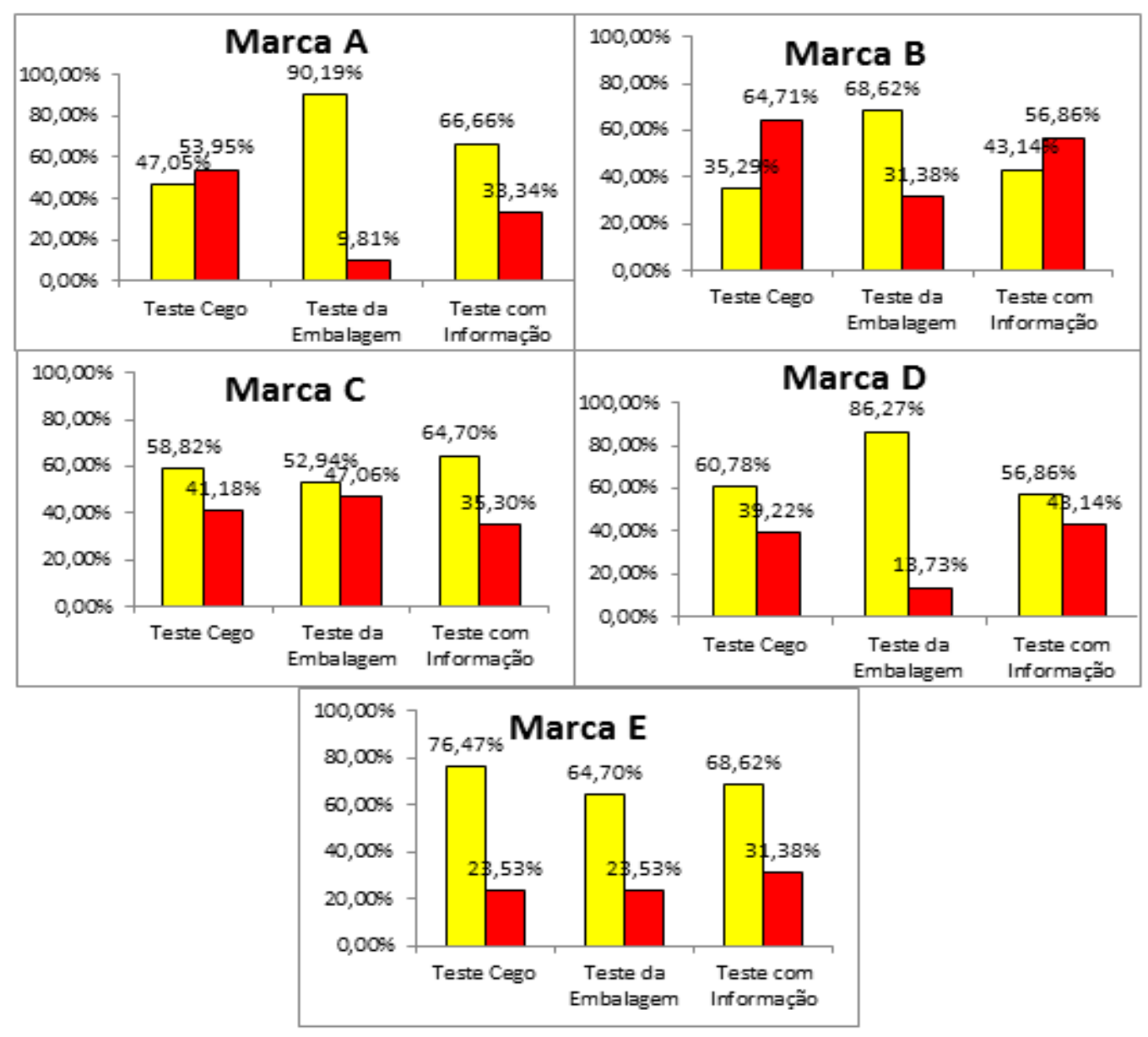


A marca E apresentou maior média de aceitação no teste cego (76,47\%), e a marca B apresentou menor média de aceitação (35,29\%). No teste da embalagem, a Marca A apresentou maior média de aceitação (90,19\%), e a marca C apresentou menor média de aceitação (52,94\%). Já no teste com informação, novamente as marcas E e B apresentaram maior e menor média de aceitação, respectivamente, porém a marca E apresentou média menor que no teste cego, e a marca $B$ apresentou média maior de aceitação.

As médias de aceitação das cinco marcas de suco de laranja industrializado nas três sessões de análise foram representadas (Figura 5). Foi possível observar uma diferença significativa entre as médias de aceitação de cada marca de suco de laranja industrializado na análise de variância para os dados obtidos em cada uma das sessões; assim, procedeu-se ao teste de Tukey para a comparação das médias.

Figura 5 - Médias de aceitação das cinco marcas de suco de laranja industrializado, avaliadas nos três testes de aceitação (teste cego, teste da embalagem, teste com informação). Pares de médias com a mesma letra não diferem entre si pelo teste de Tukey ( $p>0,05)$.

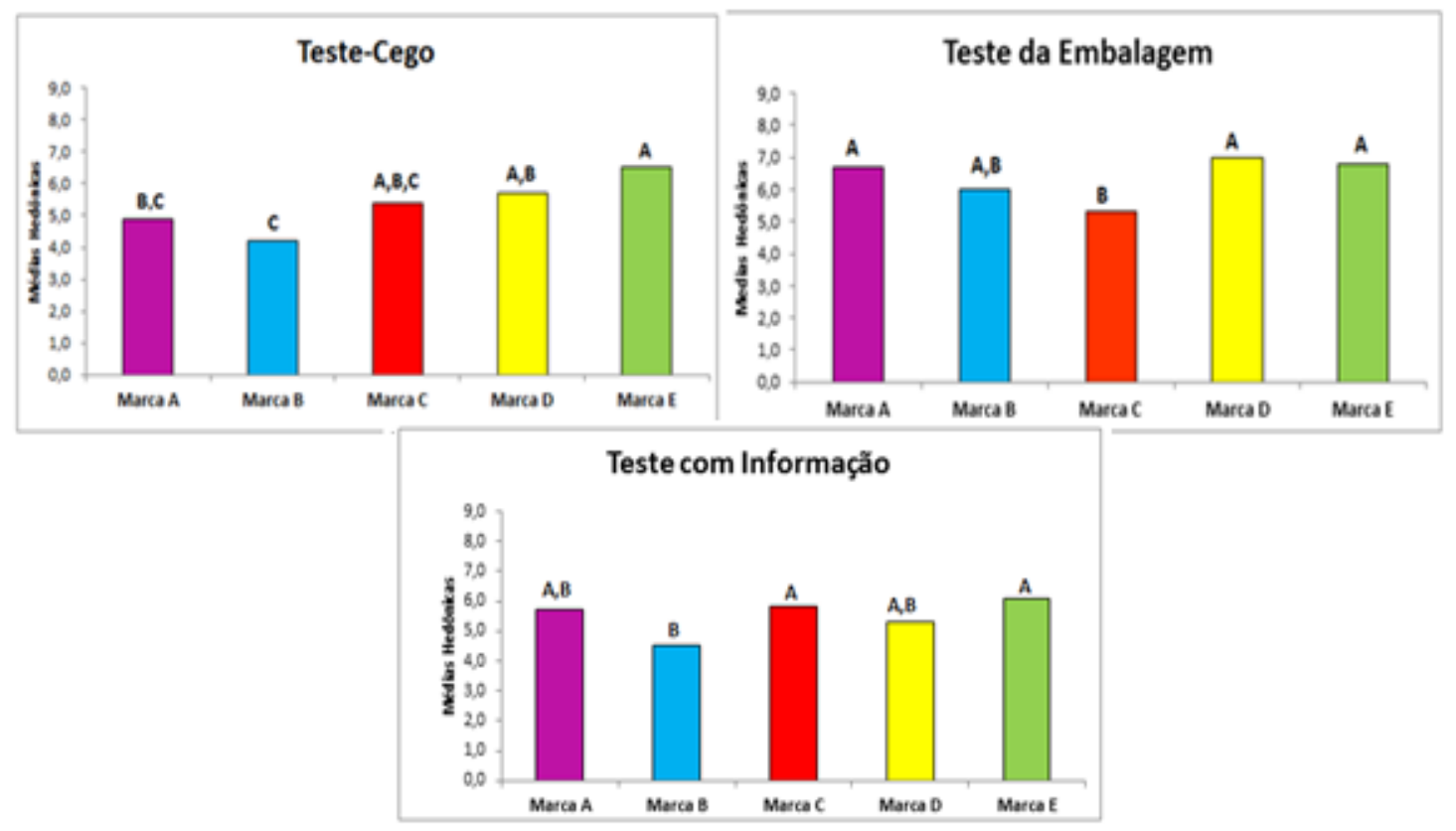

Na sessão 1 (teste cego), observou-se que as médias de aceitação variaram entre 4,2 (para a marca B) e 6,5 (para a marca E), situando-se entre os termos "desgostei ligeiramente" e "gostei moderadamente". Nesta sessão, as comparações B vs. E, B vs. D e A vs. E diferiram entre si $(p<0,05)$ sendo a marca B a de aceitação mais baixa. 
No teste da embalagem (sessão 2), as médias de aceitação variaram entre 5,3 (para a marca C) e 7,0 (para a marca D), ficando entre os termos hedônicos "indiferente" e "gostei moderadamente". As marcas A, B, D e E não diferiram entre si ( $p>0,05)$, porém foram diferentes da marca $C(p<0,05)$, que obteve a menor média $(5,3 \%)$ quando comparada às outras marcas.

Já na última sessão (teste com informação), as médias de aceitação variaram entre 4,5 (marca B) e 6,1 (marca E), ficando entre os termos hedônicos "desgostei ligeiramente" e "gostei ligeiramente". A marca B se diferenciou da marca C e E $(\mathrm{p}<0,05)$, que foram as mais aceitas pelos consumidores, e se igualou as demais marcas (A e D).

\section{DISCUSSÃO}

Foi possível notar nas características demográficas dos consumidores, que a maior parte dos participantes do estudo era do sexo feminino e possuía curso superior incompleto, isso se deve ao fato de a análise sensorial ter sido realizada entre alunos do Curso de Nutrição e a maior parte dos participantes eram estudantes do curso de graduação.

Dos participantes desse estudo, 23,5\% afirmaram consumir suco industrializado pelo menos 2 vezes por semana, sendo esse resultado inferior ao encontrado por Sartório10 e Carmo e Dantas ${ }^{11}$, uma vez que, em ambos os estudos, os participantes afirmaram ter o hábito de consumir algum tipo de suco três ou mais vezes por semana. Vale ressaltar que, no presente estudo, a questão se relacionava ao hábito de consumir suco industrializado, e não qualquer tipo de suco, o que poderia justificar as diferenças encontradas.

Verificou-se que o prazo de validade foi a característica mais mencionada como importante de se observar nos rótulos dos produtos, resultado semelhante ao de Bendino $^{12}$. Segundo este autor, essa informação é considerada importante pelo fato de o consumidor associar a qualidade do alimento com a validade, uma vez que um produto vencido acarreta danos financeiros e à saúde e financeiros.

O fato de as informações nutricionais terem sido a segunda característica mais citada vai de encontro ao encontrado por Carmo e Dantas11 que, buscando caracterizar o mercado de sucos prontos para o consumo, observaram que somente $50 \%$ dos consumidores afirmaram ler as informações nutricionais contidas nos rótulos. Ressalta-se aqui a importância do papel do nutricionista na promoção da educação 
alimentar e nutricional, para que tais informações sejam compreensíveis pelo consumidor e, portanto, mais determinantes do processo de decisão de compra ${ }^{13,14}$. Quanto ao preço, Sartório10 afirma ser este um dos fatores determinantes para a decisão de compra. De acordo com Keller ${ }^{15}$, o preço é uma importante consideração da marca, uma vez que os consumidores o relacionam com seu valor e percepção de qualidade. $\mathrm{O}$ autor ainda afirma que em diversas categorias de produtos os clientes percebem a qualidade com base no preço cobrado para, assim, formar a percepção de valor.

A maior parte dos participantes do estudo afirmou consumir uma marca de suco com maior frequência. $\mathrm{O}$ fato de o consumidor preferir sempre a mesma marca está relacionado com as experiências que ele já teve com o produto anteriormente, visto que, quando uma marca atende às expectativas do consumidor, essa ganha sua preferência e fidelidade ${ }^{16,17}$.

Comparando esses resultados apresentados na Figura 3 com os demonstrados pela Figura 4, foi possível observar que as marcas citadas como as consumidas com maior frequência pelos participantes do estudo, não foram bem aceitas quando avaliadas no teste cego, porém, quando avaliadas juntamente com suas respectivas embalagens, verificou-se aumento significativo da aceitação do produto. Esse é um fator interessante que revela como a marca pode exercer uma influência positiva sobre o produto. $\mathrm{O}$ valor da marca é caracterizado por um conjunto de recursos que agregam ou subtraem valor a um produto, entusiasmando os clientes a reagirem positiva ou negativamente aos estímulos do marketing de uma marca ${ }^{18}$.

Verificou-se que, para todas as marcas, houve modificação da nota entre as três diferentes sessões, sendo que, para algumas marcas, as notas melhoraram e, para outras, as notas pioraram quando as amostras foram servidas com as respectivas embalagens (terceira sessão), em relação ao teste cego. Este fato evidencia a influência positiva ou negativa da marca sobre o consumidor, que pode distorcer sua resposta devido ao poder de determinada marca ${ }^{19}$. Assim, verificou-se que as marcas A, B e C influenciam de maneira positiva a aceitação dos consumidores, pois, comparando-se os resultados do teste cego com o teste com informação, ocorreu aumento da porcentagem de consumidores que gostaram das mesmas (notas entre 6 e 9) e redução da frequência dos consumidores que não gostaram dessas marcas (notas entre 1 e 5 ). 
A marca A demonstrou maior influência positiva na aceitação dos consumidores quando comparada às marcas B e C, uma vez que, no teste cego, obteve apenas 47,0\% de notas boas e no teste com informação, o percentual de notas subiu para $66,6 \%$, aumentando em $19,6 \%$ o percentual de consumidores que avaliaram positivamente o produto. Já para as marcas B e C, as notas boas aumentaram em apenas 7,8\% e $5,9 \%$, respectivamente. Porém, apesar de a marca A ter exercido influência positiva sobre a aceitação dos consumidores, 53,9\% dos mesmos desgostaram deste suco no teste cego. Esse resultado mostra a necessidade de investimento na melhoria da qualidade sensorial desta marca de suco. Este mesmo comportamento foi observado em vários estudos avaliando a influência da marca sobre algum produto, confirmando que as características não sensoriais influenciam a aceitação dos consumidores ${ }^{19,20,21}$.

Para as marcas D e E, observa-se que, no teste com informação, houve aumento de $3,9 \%$ e $7,8 \%$, respectivamente, da porcentagem de consumidores que não gostaram das marcas (notas entre 1 e 5). Apesar de ter sido um percentual baixo, as marcas D e E influenciaram negativamente na aceitação dos consumidores. No teste cego 60,8\% dos consumidores gostaram da marca D e 76,5\% dos consumidores gostaram da marca $\mathrm{E}$ (notas entre 6 e 9). Isto mostra que esses produtos apresentam boa qualidade sensorial, porém, falta-lhes investimento nas estratégias de marketing e propaganda para ajudar a fortalecer essas marcas perante aos consumidores.

Os resultados apresentados no teste de médias e análise de variância permitiram observar uma diferença significativa entre as médias de aceitação de cada marca de suco de laranja industrializado.

Na sessão 1 (teste cego), pode-se observar que os consumidores posicionaram suas notas na parte média da escala. Este resultado foi semelhante ao encontrado por Della Lucia $^{20}$, que afirmou que essa postura indica que os consumidores se mostraram inibidos ao julgar as amostras devido à ausência de identificação das mesmas, o que impossibilitou explorar toda a amplitude da escala. Ainda nesta sessão, foi possível observar que houve pouca variação nas médias de aceitação, este resultado mostra que os consumidores não perceberam muita diferença entre as marcas de suco estudadas, talvez por não estarem cientes da marca do produto que eles estavam degustando. 
No teste da embalagem (sessão 2), notou-se que a marca C obteve a menor média de aceitação quando comparada às outras marcas. Esse resultado já era esperado, uma vez que, segundo os comentários fornecidos pelos voluntários durante o teste, a marca $\mathrm{C}$ era uma marca menos popular em relação às outras marcas. De acordo com Gerges $^{22}$, marcas conhecidas trazem uma segurança a mais para o consumidor, gerando um vínculo.

\section{CONCLUSÃO}

Os dados obtidos permitiram confirmar que a informação sobre a marca influencia a avaliação do consumidor a respeito do produto. Neste estudo, a informação sobre a marca exerceu influência positiva para as marcas A, B e C. Já para as marcas D e E, a informação sobre o produto diminuiu a porcentagem de consumidores que gostaram do produto, indicando que estes sucos podem ser preferidos quando as intervenções da marca são eliminadas. Com base nisto, os resultados encontrados reforçam a importância da marca, da embalagem e das associações feitas a elas para a construção de uma imagem para o consumidor, que atenda às expectativas e possa, gradativamente, conquistar seu afeto.

\section{REFERÊNCIAS}

1. Contini C, Boncinelli F, Gerini F, Scozzafava G, Casini, L. Investigating the role of personal and context-related factors in convenience foods consumption. Appetite. 2018;12:26-35.

2. Silva PT, Fialho E, Lopes MLM, Valente-Mesquita VL. Sucos de laranja industrializados e preparados sólidos para refrescos: estabilidade química e físico-química. Revista Ciência e Tecnologia de Alimentos. 2005;25(3):597-602.

3. Brasil. Ministério da Agricultura, Pecuária e Abastecimento. Decreto $n^{0} 2.314$, de 04 de setembro de 1997. Regulamenta a Lei no 8.918, de 14 de julho de 1994, que dispõe sobre a padronização, a classificação, o registro, a inspeção, a produção e a fiscalização de bebidas. [acesso 2020 julho 08]. Disponível em: $<$ http://extranet.agricultura.gov.br/sislegisconsulta/consultarLegislacao.do?ope racao=visualizar\&id $=1010>$

4. Brasil. Ministério da Agricultura, Pecuária e Abastecimento [Internet]. Decreto $\mathrm{n}^{0} 3.510$, de 16 de junho de 2000. Altera dispositivos do Regulamento aprovado pelo Decreto $n^{0} 2.314$, de 4 de setembro de 1997, que dispõe sobre a padronização, a classificação, o registro, a inspeção, a produção e a fiscalização de bebidas. [acesso 2020 julho 08]. Disponível em:

$<$ http://extranet.agricultura.gov.br/sislegisconsulta/consultarLegislacao.do?operacao=visualizar\&id=1012> 
5. Franco ASM. Análise Conjuntural: O suco de laranja brasileiro no mercado global. 2016;38:11-12.

6. De Barros JRM, de Barros ALM, Cypriano MP. O mercado da citricultura no Brasil e as suas novas perspectivas, 2019. Disponível em:

http://citrusbr.com.br/download/biblioteca/CitrusBR_Livro_Concecitrus_2016 .pdf

7. Ribeiro, APS. A influência do valor de marca na decisão de compra dos jovens universitários das classes A e B. In: XXXII Congresso Brasileiro de Ciências da Comunicação. Curitiba, PR, 2009.

8. Kotler P, Keller KL. Administração de Marketing. 12. ed. São Paulo: Pearson Prentice Hall, 2006.

9. Della Lucia SM, Minin VPR, Silva CHO, Minin LA, Ceresino EB. Expectativas geradas pela marca sobre a aceitabilidade de cerveja: estudo da interação entre características não sensoriais e o comportamento do consumidor. Boletim do Centro de Processamento de Alimentos. 2010;28(1):11-24.

10. Sartório A. Os fatores que influenciam a compra dos sucos prontos industrializados. 2006. 70 f. Centro Universitário de Brasília, Brasília, 2006.

11. Carmo MCL, Dantas MIB. Caracterização do mercado consumidor de sucos prontos para o consumo. Brazilian Journal of Food Technology. 2014;17(4):1-5.

12. Bendino NI, Popolim WD, Oliveira CRA. Avaliação do conhecimento e dificuldades de consumidores frequentadores de supermercado convencional em relação à rotulagem de alimentos e informação nutricional. Journal of Health Science Institue. 2012;30(3):261-265.

13. Ricci BCDSM. A forma de apresentação das informações nutricionais em embalagens de alimentos e o impacto na decisão de compra dos pais, 2016.152f. Dissertação de Mestrado. Pontifícia Universidade Católica Do Rio Grande Do Sul - Pucrs.

14. Miklavec K, Pravst I, Grunert KG, Klopcic M, Pohar J. The influence of health claims and nutritional composition on consumer's yoghurt preferences. Food Quality and Preference. 2015;43:25-33.

15. Keller KL. Gestão estratégica de marcas. São Paulo: Prentice-Hall. 2005.

16. Kotler P. Administração de marketing: a edição do novo milênio. São Paulo: PrenticeHall, 2000. 764 p.

17. Oliveira DS. Um estudo sobre a influência das marcas no processo decisório de compra do consumidor sob o ponto de vista teórico. 2010. 69 f. Monografia (Graduação em Administração) - Faculdade AGES, Paripiranga.

18. Aaker DA. Marcas: Brand Equity, gerenciando o valor da marca. Gulf Professional Publishing. São Paulo: Elsevier, 1998.

19. Minnin VPR, Milagres MP, Silva RCSN, Vasconcelos CM, Martins EMF, Sampaio SCS. Análise de risco na avaliação da influencia da marca na aceitabilidade não sensorial de requeijão cremoso. Revista do Instituto de Laticinios Cândido Tostes. 2012; 387(67):79-85.

20. Della Lucia SM. Métodos estatísticos para a avaliação da influencia de características não sensoriais na aceitação, intenção de compra e escolha do consumidor. 2008. 116 f. Universidade Federal de Viçosa, Viçosa, MG. 
21. Eberle LE, Erlo FL, Milan GS, Lazzari, F. Um estudo sobre determinantes da intenção de compra de alimentos orgânicos. Revista de Gestão Social e Ambiental. 2019;13(1): 94-111.

22. Gerges NRC. Influência da Forma do Anúncio de Preço Comparativo e do Conhecimento da Marca na Intenção de Compra. In: $3^{\circ}$ Congresso Latino Americano de Varejo. Rio de Janeiro, RJ, 2010.

Submissão: 12/04/2018

Aprovação: 15/08/2020 